\section{Authenticate new xenograft models}

As the US National Cancer Institute (NCI) switches to using patient-derived tumour xenografts in mice for drug screening (see Nature 530, 391; 2016), we warn researchers on behalf of the International Cell Line Authentication Committee (go.nature.com/kphqtx) that xenografts potentially have the same cross-contamination and misidentification problems as cultured cell lines.

For example, at least 4 of the 60 human-cancer cell lines on NCI's panel are affected, as are several NCI-derived lines that were established before contamination testing became widely available (see go.nature.com/csodfc).

Lack of testing or bad practice can undermine the reliability of patient-derived xenografts. Cell cultures from these call for extra quality-control measures, such as screening for cross-species DNA contamination (J. Camps et al. Leuk. Res. 30, 923-934; 2006).

The US National Institutes of Health now requires the authentication of key biological resources, but guidelines and defined protocols are still needed for rigorous characterization of patient-derived xenografts. It will be essential to deposit reference information for cell-based models in public databases, including details of donor DNA profile, host species and strain, testing outcome for host DNA, and methodologies.

Roland M. Nardone Silver Spring, Maryland, USA. Roderick A. F. MacLeod Leibniz Institute DSMZ, Germany. Amanda Capes-Davis Children's Medical Research Institute, New South Wales, Australia. acapes-davis@cmri.org.au

\section{Science primers in the courtroom}

David Neuberger suggests that scientific primers could help to speed up legal proceedings
(Nature 531, 9; 2016). In the United States, the Federal Judicial Center and the National Academies of Sciences, Engineering, and Medicine have prepared such primers for judges in the form of a reference manual (see go.nature.com/ntqkvf).

Judges in other countries have used this manual to understand disputes over scientific evidence. The Argentinian judiciary has prepared 15 similar guides modelled on chapters of the US reference manual. The Canadian judiciary, through its National Justice Institute, has used it to prepare four supplementary chapters that deal with specific concerns in Canadian courts. The judiciaries of China, Japan and several others are also exploring ways to incorporate sections of the US manual into judicial-education programmes.

As co-chairs of the National Academies' Committee on Science, Technology, and Law, we find that engagement between our communities creates new understandings and strengthens the foundation for decisionmaking within both groups. The two communities should seek more opportunities to discuss science in the courtroom and law in the laboratory.

David Baltimore California Institute of Technology, Pasadena, USA.

David S. Tatel US Court of Appeals for the District of Columbia Circuit, Washington DC, USA. baltimo@caltech.edu

\section{IPBES reaches out to social scientists}

The Intergovernmental SciencePolicy Platform on Biodiversity and Ecosystem Services (IPBES) has issued a call for experts to perform its global assessment (see go.nature.com/g5zc3e). The call, which closes on 5 May, emphasizes the need to nominate more social scientists (see also A. B. M. Vadrot et al. Nature 530, $160 ; 2016$ and K. Reuter et al. Nature 531, 173; 2016).
A strong collective effort is necessary to reach scholars outside the natural sciences, because they might not consider themselves to be biodiversity researchers. To this end, IPBES is reaching out to learned social-science societies (of sociology, economics, geography, anthropology, political science and psychology, among others), to networks of scientists and to prominent interdisciplinary international programmes such as Future Earth.

A special procedure to fill gaps in expertise, including in the social sciences, was adopted at the IPBES fourth plenary (further suggestions to secretariat@ipbes.net are welcome). Success ultimately depends on governments and organizations stepping up to nominate more social scientists. Anne Larigauderie IPBES Secretariat, Bonn, Germany. Marie Stenseke University of Gothenburg, Sweden.

Robert T. Watson Potomac, Maryland, USA.

secretariat@ipbes.net

\section{Self-built labware stimulates creativity}

Adapting open-source online designs for the assembly of scientific equipment is useful for cost-cutting (Nature 531, 147-148; 2016). Just as important from an educational viewpoint is the resourcefulness and creativity that such 'open hardware' can stimulate in customizing it to address scientific goals.

My graduate students have used open-source electronic modules and 3D printing over the past three years to generate prototype devices for research in applied chemistry. Their limited experience in electronics is not a problem because the equipment is not expensive - plenty of opensource printed circuit boards have been discarded without denting the lab's budget. Crucially, the end products worked and furnished useful data (see also P. L. Urban
Analyst 140, 963-975; 2015). Pawel Urban National Chiao Tung University, Hsinchu, Taiwan. plurban@nctu.edu.tw

\section{A different take on Indus evidence}

As a scholar of the Indus script since the 1990s, I take issue with many of the statements in Andrew Robinson's summary (Nature 526, 499-501; 2015 and Nature 532, 308; 2016) of his book The Indus: Lost Civilizations (Reaktion, 2015).

In my view, there are climatic, geological and inter-regional motivations for the end of urbanization in the Indus. I dispute that there is evidence for Hinduism's roots in the Indus Valley. And my inference from photos of the many axes, spearheads and arrowheads in site reports is that the Indus people had military weapons.

I consider standard usage of the term pictograph in archaeology to be a symbol, with no linguistic counterpart, representing a real or mythical object. A sign or character representing a word or phrase, such as those used in shorthand and some writing systems, is a logogram. My reading of the decipherments of Mayan and Linear B does not chime with Robinson's précis. Finally, I dislike the way he elides code-breaking and decipherment.

A point-by-point discussion of these and other issues can be found in my books (Epigraphic Approaches To Indus Writing; Oxbow, 2011; The Archaeology and Epigraphy of Indus Writing; Archaeopress, 2015), which demonstrate the potential of digital techniques to move this field forward.

The Indus peoples, like all other archaeological cultures, had the same range of foibles and brilliance we all share. We owe it to them to make our representations of their writing and culture as precise as possible. Bryan K. Wells Victoria, Canada. bdkj.wells@gmail.com 